\title{
Use of VO2 vs Static Compliance for Determination of Optimal PEEP in ARDS Patients
}

\author{
ZAHRET EL-WADY M.S. MOHAMED, M.B.B.Ch.; MOHAMED S. ABD EL-GHAFAR, M.D.; \\ GHADA F. EL-BARADEY, M.D. and SALAH EL-DIN I. EL-SHERIF, M.D. \\ The Department of Anesthesiology and Surgical Intensive Care, Faculty of Medicine, Tanta University, Tanta, Egypt
}

\begin{abstract}
Background: Protective ventilation strategies using low tidal volume, limiting plateau pressure and manipulating $\mathrm{FiO}_{2-}$ PEEP combination to reach target oxygenation are standard for treatment of ARDS patients. However, the appropriate PEEP level for ventilating such individuals has not been established.
\end{abstract}

Aim of Study: The study investigated the effect of VCO2 guided PEEP vs static compliance guided PEEP on oxygenation, $\mathrm{CO} 2$ elimination, alveolar ventilation and static compliance in ARDS patients.

Patients and Methods: This prospective randomized controlled study was conducted at a tertiary university hospital ICU including sixty mechanically ventilated ARDS patients. Patients were randomized between two groups; Group A, where PEEP was titrated using static compliance and Group $\mathrm{B}$, where PEEP was titrated using $\mathrm{VCO} 2$, once it failed to recover to baseline, the preceding PEEP value was considered optimum.

Results: Both groups received comparable values of PEEP applied $(p \leq 0.499)$. This resulted in a significant increase in $\mathrm{SpO}_{2}, \mathrm{PaO}_{2}, \mathrm{PaO}_{2} / \mathrm{FiO}_{2}, \mathrm{VA}$ and static compliance from baseline ( $p \leq 0.001$ in both groups), with no significant difference between the two groups. Mean and standard deviation of $\mathrm{VCO} 2$ showed a significant increase from baseline $(221.37 \pm 44.582$ vs $225.10 \pm 46.42 ; p \leq 0.004)$ in Group B with no significant difference between two groups. Two cases in Group A had a decrease in VCO 2 from baseline and one showed both a decrease in VCO 2 from baseline and MAP below $65 \mathrm{mmHg}$. Despite that mean and standard deviation of MAP doesn't significantly change from baseline ( $90.00 \pm$ 17.76 vs $89.50 \pm 17.57 ; p \leq 0.5006$ and $86.83 \pm 16.47$ vs $85.27 \pm$ $17.43 p \leq 0.1577$ ) in both groups, and showed no significant difference between the two groups.

Conclusion: Using VCO2 to determine optimum PEEP associated with comparable improvement in oxygenation and lung compliance, while resulting in a significant improvement in $\mathrm{CO} 2$ elimination compared with optimum PEEP determined by static compliance in ARDS patients. It was, also, associated with no complication in terms of hemodynamic stability in contrast to optimum PEEP determined by static compliance

Correspondence to: Dr. Zahret El-Wady M.S. Mohamed, E-Mail: zahretelwady89@gmail.com. which was associated with incidence of hemodynamic instability.

Key Words: Hypoxia - ARDS - Optimal PEEP - VCO2.

\section{Introduction}

ACUTE Respiratory Distress Syndrome (ARDS) is a major cause of acute respiratory failure. Its development leads to high rates of mortality, as well as short-and long-term complications, such as physical and cognitive impairment. Therefore, early recognition of this syndrome and application of demonstrated therapeutic interventions are essential to change the natural course of this devastating entity [1]

Protective ventilation strategies, low circulating volumes and elevated PEEP levels have been introduced and evaluated in different clinical studies. As a result, this strategy has become a standard for treatment of such patients. However, the appropriate PEEP level for ventilating such individuals has not been established [2].

Optimal PEEP levels are those that maximize oxygenation of the tissues without causing overdistention of alveoli or affecting patient's hemodynamics. Optimal PEEP determination can be done using different strategies as ABG's, cardiac output measurements, $\mathrm{A}-\mathrm{V} \mathrm{O}_{2}$ content differences or mixed venous $\mathrm{PO}_{2}[3]$. Among these, several studies has suggested the use of static compliance in determination of optimal PEEP and argued the clear benefit of its use in assessment of lung recruitment [4].

$\mathrm{VCO} 2$ obtained from volumetric capnogram is a noninvasive, fast, reliable and safe bedside monitoring tool, but monitoring and analysis of changes in $\mathrm{VCO}_{2}$ to determine optimum PEEP have not 
been tested so far. Therefore, in the present study we hypothesized using $\mathrm{CO}_{2}$ production $\left(\mathrm{VCO}_{2}\right)$ obtained from volumetric capnogram to determine optimum PEEP by using $\mathrm{VCO} 2$ value as a guide for early detection of side effect of increasing PEEP on cardiac output. The present study assumed that failure of $\mathrm{VCO} 2$ level to recover to baseline after application of certain PEEP level higher than optimal value, will be observed earlier than any change in MAP and can be used as an indicator of decreased cardiac output. Optimal PEEP detection using static compliance was used as a control group.

The primary outcome of the study is to collect and compare data about $\mathrm{PaO}_{2} / \mathrm{FiO}_{2}$ while the secondary outcome is collect and compare data about PEEP, oxygenation $\left(\mathrm{SpO}_{2}, \mathrm{PaO}_{2}\right), \mathrm{VCO} 2$, alveolar ventilation (VA) and static compliance and monitor complications as hemodynamic instability and pneumothorax.

\section{Patients and Methods}

This was a prospective randomized study. The collected data was conducted during the period from March 2016 to March 2017. After approval from Institutional Ethics Committee, an informed consent from all participants' relatives was obtained. All patients' data was confidential with secret codes and private files for each patient. All given data were used for the current medical research only.

\section{Sample size:}

The sample size was calculated using Epi-Info software statistical package created by World Health organization and center for Disease Control and Prevention, Atlanta, Georgia, USA version 2002. The sample size was calculated at $\mathrm{N}=30$.

The criteria used for sample size calculation were as follows:

- $95 \%$ confidence limit.

- $80 \%$ power.

- The ratio between experimental and control groups is $1: 1$.

- The outcome in the Group A is 55\% while in the Group B is $88 \%$.

\section{Study population:}

Inclusion criteria:

Over the study period, patients admitted to the surgical ICU on mechanical ventilation via an orotracheal tube and fulfilling Berlin Definition to confirm the criteria of ARDS, were registered.
All patients who had ARDS and $\mathrm{PaO}_{2} / \mathrm{FiO}_{2}$ ratio $<300$ were selected then ARDS grade was classified.

\section{Berlin definition of ARDS [5]:}

- Acute onset within one week.

- Patients can be classified with either mild $\left(\mathrm{PaO}_{2} / \mathrm{FIO}_{2} \leq 300 \mathrm{mmHg}\right)$ moderate $\left(\mathrm{PaO}_{2} / \mathrm{FIO}_{2}\right.$ $\leq 200 \mathrm{mmHg})$ and severe $\left(\mathrm{PaO}_{2} / \mathrm{FIO}_{2} \leq 100 \mathrm{mmHg}\right)$ disease with PEEP or Continuous Positive Airway Pressure (CPAP) > $5 \mathrm{cmH} 2 \mathrm{O}$ [5] .

- Bilateral lung opacities consistent with pulmonary edema on computered tomography or chest radiogram not explained by cardiac failure or fluid overload.

\section{Exclusion criteria:}

The study excluded patients suffering from (cardiac, hepatic, renal) disease or with unstable hemodynamic.

Study design:

Patients who met the previous criteria were enrolled in the study. The patients were randomized using closed envelop into two equal groups of 30 patients.

\section{Patients were subdivided into:}

Group A: PEEP was increased in steps of 2 $\mathrm{cmH}_{2} \mathrm{O}$ every 20 minutes and changes in static compliance was calculated and monitored. The highest static compliance was considered to be the best PEEP. If at 2 different PEEPs the static compliance was identical, we chose the one with the lower PEEP.

Group B: PEEP was increased in steps of 2 $\mathrm{cmH}_{2} \mathrm{O}$ every 20 minutes and changes in $\mathrm{VCO} 2$ were monitored. If $\mathrm{VCO} 2$ failed to recover to baseline value, the previous reading of PEEP was considered optimum PEEP.

Oxygenation goal: The oxygen goal was a minimum of $\mathrm{PaO}_{2} 55-80 \mathrm{mmHg}$ or $\mathrm{SpO}_{2} 88-95 \%$ as recommended by ARDS network trial [6] .

\section{Study intervention:}

- Baseline ventilation: All patients were ventilated with Engström Carestation-GE ventilator, USA. The patients received volume controlled time cycled ventilation and the VT was maintained between $(6-8 \mathrm{ml} / \mathrm{kg})$ of predicted body weight calculated in males as 50+0.91 [height $(\mathrm{cm})$ 152.4 ] and females as $45.5+0.91$ [height $(\mathrm{cm})$ 152.4]. 
At baseline, fraction of inspired oxygen ( $\mathrm{FiO} 2)$ was initially set at $40 \%$, PEEP was set at $5 \mathrm{cmH}_{2} \mathrm{O}$ and inspiratory to expiratory ratio at 1:2 while the plateau pressure (Pplat) and respiratory rate was set according to ARDSNET protocol [6].

- Data collected: Peak airway pressure and PEEP were collected using ventilator display. Plateau pressure was measured by using inspiratory hold button on ventilator for 3 seconds. Static compliance was calculated by measuring corrected tidal volume divided by (Plateau pressure-PEEP) and $\mathrm{VA}$. $\mathrm{VCO} 2$ from volumetric capnogram module readings of the ventilator by mainstream $\mathrm{CO} 2$ sensor placed between the tracheal tube and ventilator tubing's was recorded.

- Monitoring: Patient's blood pressure was monitored by noninvasive blood pressure, Heart Rate (HR) and rhythm and $\mathrm{SpO}_{2}$ using Nihon Kohden BSM-2301K, Japan monitor.

-PEEP titration protocol: Adequate sedation (Richmond agitation sedation scale score-5) [7] was achieved with continuous infusions of midazolam of $0.1 \mathrm{mg} / \mathrm{kg} / \mathrm{h}$ and paralyzed with bolus injection of $3 \mathrm{mg}$ cisatracurium as needed during PEEP titration and patient kept in supine position. A radial arterial catheter and triple-lumen central venous catheter (via the subclavian or internal jugular vein) was inserted for frequent sampling of arterial blood gas and central venous blood gas analysis respectively using the AVL-988.

After baseline ventilation, recruitment maneuver in the form of sustained application of PEEP at $40 \mathrm{cmH}_{2} \mathrm{O}$ for 40 seconds then baseline hemoglobin level, arterial blood gas and central venous blood gas samples were obtained as input data for volumetric capnogram module.

- Complications during study period: Hemodynamic instability in the form of hypotension with a mean blood pressure value of less than $65 \mathrm{mmHg}$ was treated by incremental dose of $5 \mathrm{mg}$ ephedrine and PEEP change to previous level.

\section{Weaning:}

Weaning and extubation were done according to the preset weaning protocol of the SICU.

\section{Statistical analysis:}

The collected data were organized, tabulated and statistically analyzed using SPSS Version 19 (Statistical Package for Social Studies) created by IBM, Illinois, Chicago, USA. For numerical values the range mean and standard deviations were calculated. The differences between mean values of the two studied groups were tested using student's $t$-test. Differences of mean values between mean values at baseline and end of intervention were tested using paired $t$-test. For categorical variable, the number and percentage were calculated. The level of significance was adopted at $p<0.05$.

\section{Results}

Sixty patients who fulfilled the Berlin definition of ARDS [8] were enrolled. Demographic data and ARDS grade for each registered patient were collected (Table 1).

There was no significant difference values of PEEP applied between two groups $(p \leq 0.499)$. The baseline values of $\mathrm{SpO} 2, \mathrm{PaO}_{2}$ and $\mathrm{PaO}_{2} / \mathrm{FiO}_{2}$ were comparable in both groups. Both groups showed a significant increase in $\mathrm{SpO} 2, \mathrm{PaO}_{2}$ and $\mathrm{PaO}_{2} / \mathrm{FiO}_{2}$ from baseline ( $p \leq 0.001$ in both groups), with no significant difference between the two groups (Table 2).

The baseline values of $\mathrm{VCO} 2$, VA and MAP were comparable in both groups. VA values were significantly improved in both groups $(p \leq 0.001$ in both groups), with no significant difference between the two groups. $\mathrm{VCO} 2$ showed a significant increase from baseline $(p \leq 0.001)$ in Group B with no significant difference between two groups. Two cases in Group A had a decrease in $\mathrm{VCO} 2$ from baseline while one showed both a decrease in $\mathrm{VCO} 2$ from baseline and MAP below $65 \mathrm{mmHg}$. Despite that mean and standard deviation of MAP doesn't significantly change from baseline in both groups, and showed no significant difference between the two groups (Table 2).

The static compliance in both groups showed a significant increase from baseline values $(p \leq 0.001$ in both groups) with no significant difference between the two groups (Table 2).

Table (1): Comparison between demographic data between studied groups.

\begin{tabular}{lllll}
\hline & Group A & Group B & $\chi^{2}$ & $p$ \\
\hline $\begin{array}{l}\text { Sex: } \\
\quad \text { Males }\end{array} \quad 20$ & 22 & 0.317 & 0.57 \\
$\quad$ Females & 10 & 8 & & \\
Age: & & & & \\
$\quad$ Range & $16-57$ & $16-62$ & $t$ & $p$ \\
$\quad$ Mean \pm SD & $37.62 \pm 11.75$ & $38.14 \pm 13.83$ & 0.73 & 0.67 \\
Predicted body weight: & & & & \\
$\quad$ Range & $61-80$ & $59-77$ & 1.54 & 0.57 \\
$\quad$ Mean \pm SD & $62.42 \pm 10.32$ & $63.63 \pm 9.50$ & & \\
\hline
\end{tabular}


Table (2): Comparison between measured data between the studied groups at baseline and end of intervention. Values are expressed as mean $( \pm \mathrm{SD})$.

\begin{tabular}{|c|c|c|c|}
\hline & Group A & Group B & $p$ \\
\hline \multicolumn{4}{|c|}{ Optimum PEEP: } \\
\hline Baseline & $5( \pm 0.0)$ & $5( \pm 0.0)$ & 0.499 \\
\hline End & $11.33 \pm 2.23$ & $10.93 \pm 2.31$ & \\
\hline$p$ & $0.001 *$ & $0.001 *$ & \\
\hline \multicolumn{4}{|l|}{ SPO2: } \\
\hline Baseline & $92.27 \pm 2.65$ & $92.83 \pm 2.55$ & 0.402 \\
\hline End & $96.33 \pm 1.69$ & $96.26 \pm 1.78$ & 0.882 \\
\hline$p$ & $0.001 *$ & $0.001 *$ & \\
\hline \multicolumn{4}{|l|}{ PO2: } \\
\hline Baseline & $73.63 \pm 11.73$ & $73.27 \pm 12.23$ & 0.906 \\
\hline End & $87.80 \pm 11.42$ & $87.53 \pm 11.74$ & 0.929 \\
\hline$p$ & $0.001^{*}$ & $0.001^{*}$ & \\
\hline \multicolumn{4}{|l|}{$\mathrm{PaO} 2 / \mathrm{FiO} 2$ : } \\
\hline Baseline & $184.08 \pm 29.34$ & $183.17 \pm 30.58$ & 0.906 \\
\hline End & $219.84 \pm 28.84$ & $219.00 \pm 29.49$ & 0.912 \\
\hline$p$ & $0.001 *$ & $0.001 *$ & \\
\hline \multicolumn{4}{|l|}{ VCO2: } \\
\hline Baseline & $218.30 \pm 37.99$ & $221.37 \pm 44.582$ & 0.775 \\
\hline End & $217.60 \pm 40.96$ & $225.10 \pm 46.42$ & 0.5096 \\
\hline$p$ & 0.751 & $0.004 *$ & \\
\hline \multicolumn{4}{|l|}{$V A:$} \\
\hline Baseline & $3.53 \pm 0.88$ & $3.73 \pm 1.05$ & 0.427 \\
\hline End & $3.73 \pm 0.93$ & $4.09 \pm 1.02$ & 0.152 \\
\hline$p$ & $0.001 *$ & $0.001 *$ & \\
\hline \multicolumn{4}{|c|}{ Static compliance: } \\
\hline Baseline & $46.16 \pm 5.94$ & $45.00 \pm 6.04$ & 0.453 \\
\hline End & $60.13 \pm 7.83$ & $58.00 \pm 7.43$ & 0.284 \\
\hline$p$ & $0.001 *$ & $0.001 *$ & \\
\hline \multicolumn{4}{|l|}{$M A P:$} \\
\hline Baseline & $86.83 \pm 16.47$ & $90.00 \pm 17.76$ & 0.477 \\
\hline End & $85.27 \pm 17.43$ & $89.50 \pm 17.57$ & 0.353 \\
\hline$p$ & 0.1577 & 0.5006 & \\
\hline
\end{tabular}

*: Significant $<0.05$.

Where:

SD : Standard Deviation

PEEP : Positive End Expiratory Pressure in $\mathrm{cmH} 2 \mathrm{O}$

FiO2 : Fraction of Inspired Oxygen expressed as $\%$.

VA : Alveolar Ventilation in L/min.

VCO2 : Volume of Carbon Dioxide in $\mathrm{ml} / \mathrm{min}$.

SPO2. : Peripheral oxygen saturation in $\%$.

$\mathrm{PaO} 2$ : Partial arterial oxygen tension in $\mathrm{mmHg}$, Static compliance in $\mathrm{mL} / \mathrm{cm} \mathrm{H} 2 \mathrm{O}$

MAP : Mean Arterial Blood pressure in $\mathrm{mmHg}$.

\section{Discussion}

It is argued that adjusting PEEP using lung mechanic [4] or alveolar ventilation and hence $\mathrm{CO} 2$ elimination [9] is superior to oxygenation in assessment of lung recruitment. In the current study we compared the use of static compliance vs. VCO 2 in determination of optimal PEEP.

To begin with, although not in ARDS patients, the comparability between combining $\mathrm{VCO} 2$ and $\mathrm{SPO}_{2}$ vs. dynamic compliance in detecting efficiency of gas exchange in obese patients undergoing recruitment to open collapsed lung was studied earlier by Tusman et al., [10] . Combining $\mathrm{VCO}_{2}$ and $\mathrm{SPO}_{2}$ demonstrated a high specificity to detect improvement in area of exchange during lung recruitment. However, in the study $\mathrm{VCO} 2$ was not used to titrate PEEP and to the best of our knowledge was never used thereafter.

In the current study, determination of optimum PEEP by monitoring $\mathrm{VCO}_{2}$ was associated with improvement of $\mathrm{CO} 2$ elimination with comparable results regarding static compliance and oxygenation when compared with the use of static compliance in ARDS patients. It was not associated with hypotension or pneumothorax. On the other hand, while using static compliance to up-titrate PEEP, two case showed a decrease in $\mathrm{VCO} 2$ with no recovery as early indicator of decrease cardiac output and one case developed manifest hypotension.

Improvement of oxygenation by using PEEP titration by $\mathrm{VCO}_{2}$ was comparable to PEEP set according to static compliance. In both groups there was a significant increase $(p \leq 0.001)$ in oxygenation parameters $\left(\mathrm{SPO}_{2}, \mathrm{PaO}_{2}\right.$ and $\left.\mathrm{PaO}_{2} / \mathrm{FiO}_{2}\right)$ with no significant difference between two groups.

In agreement with the current study results, Tusman et al., [10] demonstrated an overall increase in oxygenation parameters while using static FIO 2 during recruitment set according to dynamic compliance. While VCO2 was not used as a method for optimizing PEEP during recruitment, an increase in $\mathrm{SPO}_{2}$ was also associated with increase in $\mathrm{VCO}_{2}$.

In disagreement with the current study finding, a study by El-Baradey et al., [11] static compliance guided PEEP improved oxygenation but to a lesser extent than PEEP set according to Vd/Vt. A decrease in $\mathrm{Vd} / \mathrm{Vt}$ although not measured in the current study, but can be reflected by changes in $\mathrm{CO} 2$ elimination [12]

Pintado et al., [4] also, noted that although optimal PEEP determined by compliance had less organ dysfunction it has no significant effect on oxygenation.

Although improvement of oxygenation is targeted in ARDS patients, it was argued by Gattinoni et al., [9] that improved efficiency of alveolar ventilation and Hence, $\mathrm{CO} 2$ elimination had better prognostic value of survival compared to $\mathrm{PaO}_{2} /$ $\mathrm{FiO}_{2}$ ratio. Thus, in current study effect of PEEP on $\mathrm{VCO} 2$ and VA were, also, analyzed.

Although there was no significant difference between the two groups at end of intervention, there was a significant increase in VCO 2 from 
baseline in Group B. In Group A three cases showed a decrease in $\mathrm{VCO} 2$ with no recovery to baseline which may have contributed to the lack of significant difference in mean and standard deviation in this group from baseline.

In agreement with current study results, Tusman et al., [13] tabulated an overall increase in $\mathrm{VCO}_{2}$ level by increasing PEEP from $6 \mathrm{cmH}_{2} \mathrm{O}$ to 12 $\mathrm{cmH}_{2} \mathrm{O}$ in lavaged lung animal.

In a human study later performed by Tusman et al., [10] they tabulated an increase in VCO 2 when compliance increase. This occurred in the current study in Group B but not Group A and could be explained by applying more than optimal PEEP in Group A which caused over-distention and/or a decrease in cardiac output and hence $\mathrm{CO} 2$ delivery in some patients which decreased over all mean $\mathrm{VCO} 2$.

The lack of significant increase in $\mathrm{VCO}_{2}$ like in the current study in Group A was also, demonstrated in Ferrando et al study [14]. They found no significant difference in elimination of $\mathrm{CO} 2$ when titrating PEEP according to dynamic compliance, which again may be explained by above optimal PEEP applied.

Both groups showed a significant increase in alveolar ventilation from baseline with no significant difference between two groups.

The current study finding of increased VA from baseline in Group A was in agreement with Tusman et al., human study [10]. They noted the effect of increasing PEEP levels (ascending limb of recruitment maneuver) on increasing alveolar ventilation taking $\mathrm{VCO}_{2}$ as its marker.

In disagreement with current study finding, Tusman et al., [13] noted a decreased VA after 10 minutes of PEEP application in spite of the rise in $\mathrm{VCO} 2$. This difference in results, however, cannot be explained as an increase in VCO 2 can only occur if alveolar ventilation increase and hence, $\mathrm{CO} 2$ elimination. It may be due to the different timing of measuring VA. A ten minute window possibly didn't allow enough timing of VA recovery and increase from initial level.

Also, the current study findings were disagreement with Johnson et al., [15] results. They demonstrated a persistent decrease in VA after 20 minutes of PEEP application. This may be due to higher than optimal PEEP applied which cause a decrease in both $\mathrm{VCO} 2$ and VA.
The lack of significant difference in VA between two groups in the present study may be explained by the fact that both groups benefited from comparable levels of PEEP and recruitment maneuvers at the beginning of procedure.

In the current study, the comparison of the static compliance resulting from optimal PEEP detection by two methods was done. This demonstrated a significant increase in the static compliance of both groups from baseline with no significant difference between two groups.

The effect of titrating PEEP by $\mathrm{VCO} 2$ on static compliance was to the best of our knowledge never studied. An optimal PEEP improves static compliance. The current study suggest that $\mathrm{VCO} 2$ guided PEEP improves static compliance, however, further studies are needed to confirm this finding.

Lastly, in current study, there was no reported cases developing pneumothorax. Mean arterial blood pressure showed no significant change from baseline in both groups and no significant difference between two groups. In spite that, one case in Group A developed hypotension and decrease in $\mathrm{VCO} 2$ and two other cases showed a decrease in $\mathrm{VCO} 2$ with no recovery to baseline which is an early indicator of decrease in cardiac output.

The deficiency of static compliance method in detecting over-distention of alveoli, hence causing complication was in agreement with El-baradey et al., [11] who concluded that static compliance guided PEEP is associated with an increase in $\mathrm{Vd}$. Again since $\mathrm{CO} 2$ elimination decrease if dead space decrease, the decrease in $\mathrm{VCO} 2$ reported in group $\mathrm{A}$, also suggest that static compliance guided PEEP cause over-distention of alveoli.

In disagreement with the current study finding, Pintado et al., [4] who compared compliance-guided PEEP group or an $\mathrm{FIO}_{2}$-guided group concluded that using static compliance to detect optimal PEEP had no effect on patients' hemodynamics and resulted in more incidence of barotrauma and pneumothorax.

\section{Conclusion:}

Based on our results, we conclude that optimum PEEP determined by volumetric capnogram ( $\mathrm{VCO} 2$ monitoring) is associated with comparable improvement in oxygenation as well as lung compliance, while resulting is a significant an improvement in $\mathrm{CO} 2$ elimination compared with optimum PEEP determined by static compliance in ARDS patients. It was, also, associated with no complication in terms of hemodynamic stability in contrast to 
optimum PEEP determined by static compliance which was associated with incidence of hemodynamic instability.

\section{References}

1- MODRYKAMIEN ARIEL M. and GUPTA POOJA: The acute respiratory distress syndrome. Proceedings (Baylor University Medical Center), 28 (2): 163, 2015.

2- AMATO MARCELO BRITTO PASSOS, BARBAS CARMEN SњVIA VALENTE, MEDEIROS DENISE MACH$\mathrm{ADO}$, et al.: Effect of a protective-ventilation strategy on mortality in the acute respiratory distress syndrome. $\mathrm{N}$. Engl. J. Med., 338 (6): 347-54, 1998.

3- DÍAZ-ALERSI R. and NAVARRO-RAMÍREZ C.: High or conventional positive end-expiratory pressure in acute respiratory distress syndrome. Medicina Intensiva (English Edition), 38 (5): 311-4, 2014.

4- PINTADO MARÍA-CONSUELO, De PABLO RAÚL, TRASCASA MARÍA, et al.: Individualized peep setting in subjects with ards: A randomized controlled pilot study. Respiratory Care, 58 (9): 1416-23, 2013.

5- FORCE ARDS DEFINITION TASK, RANIERI V.M., RUBENFELD G.D., et al.: Acute respiratory distress syndrome: The berlin definition. J.A.M.A., Jun. 20, 307 (23): 2526-33, 2012.

6- NIH NHLBI ARDS: Clinical Network Mechanical Ventilation Protocol www.ardsnet.org/files/ventilator_protocol_ 2008-07.pdf; 2008 [accessed 3 Oct. 2015].

7- ELY E. WESLEY, TRUMAN BRENDA, SHINTANI AYUMI, et al.: Monitoring sedation status over time in icu patients: Reliability and validity of the richmond agitation-sedation scale (rass). J.A.M.A., 289 (22): 298391, 2003.

8- Force ARDS Definition Task: Acute respiratory distress syndrome. J.A.M.A., 307 (23): 2526-33, 2012.

9- GATTINONI L., VAGGINELLI F., CARLESSO E., et al.: Decrease in paco2 with prone position is predictive of improved outcome in acute respiratory distress syndrome. Crit. Care Med., 31 (12): 2727-33, 2003.

10- TUSMAN GERARDO, GROISMAN IVÁN, FIOLO FELIPE E., et al.: Noninvasive monitoring of lung recruitment maneuvers in morbidly obese patients: The role of pulse oximetry and volumetric capnography. Anesthesia \& Analgesia, 118 (1): 137-44, 2014.

11- EL-BARADEY GHADA FOUAD and EL-SHAMAA NAGAT SAYED: Compliance versus dead space for optimum positive end expiratory pressure determination in acute respiratory distress syndrome. Indian journal of critical care medicine: Peer-reviewed, official publication of Indian Society of Critical Care Medicine, 18 (8): 508, 2014.

12- SUNGUR MURAT and GÜVEN MUHAMMED: Lung carbon dioxide elimination corralates with physiologic dead space volume during mechanical ventilatory support. Turkish Journal of Medical Sciences, 31 (6): 529-32, 2001.

13- TUSMAN GERARDO, BOHM STEPHAN H., SUAREZSIPMANN FERNANDO, SCANDURRA ADRIANA and HEDENSTIERNA GÖRAN: Lung recruitment and positive end-expiratory pressure have different effects onON $\mathrm{CO} 2$ elimination in healthy and sick lungs. Anesthesia \& Analgesia, 111 (4): 968-77, 2010.

14- Ferrando Carlos, SUAREZ-SIPMANN FERNANDO, TUSMAN GERARDO, et al.: Open lung approach versus standard protective strategies: Effects on driving pressure and ventilatory efficiency during anesthesia-a pilot, randomized controlled trial. PloS one, 12 (5): e0177399, 2017.

15- JOHNSON JAMES L. and BREEN PETER H.: How does positive end-expiratory pressure decrease pulmonary co 2 elimination in anesthetized patients? Respiration Physiology, 118 (2): 227-36, 1999.

16-CHIKHANI M., DAS A., HAQUE M., WANG W., BATES D.G. and HARDMAN J.G.: High peep in acute respiratory distress syndrome: Quantitative evaluation between improved arterial oxygenation and decreased oxygen delivery. British Journal of Anaesthesia, 117 (5): 650-8, 2016. 


\section{إستخدام جهاز قياس حجم ثانى آكسيد الكربون

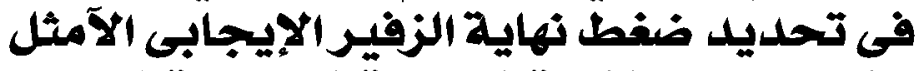 فى مرضى متلازملة الضائقة التنفسية الإيجائ الحادة}

تعتبر متلازمة العسر التففسى الحاد سبيا رئيسيا للفسل التففى الصاد. ويؤدى تطورها إلى معدلات وفاة عالية، بالإضافة إلى مضاعفات

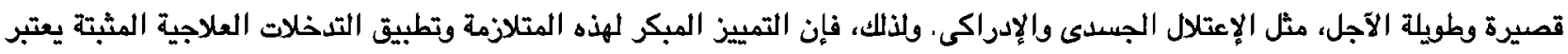

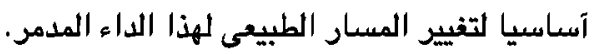

وقد تم تدابير عدة للتهوية الوقائية في دراسات سريرية مختلفة في السابق. وكتيجة لذلك، أصبحت هذه التدابير قياسية لعلاج هؤلاء المرضى.

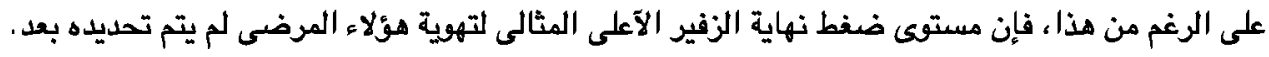

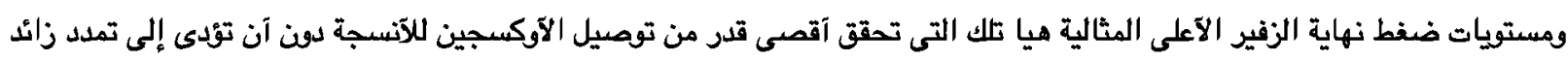

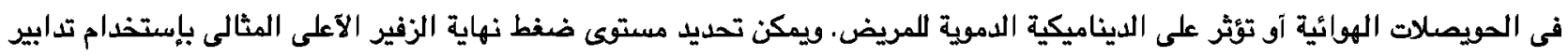

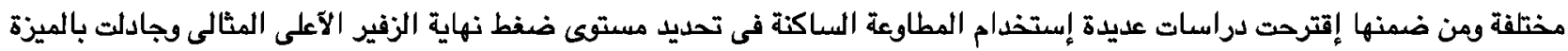
الواضحة لإستخدامها فى تقدير تجنيد الرئة.

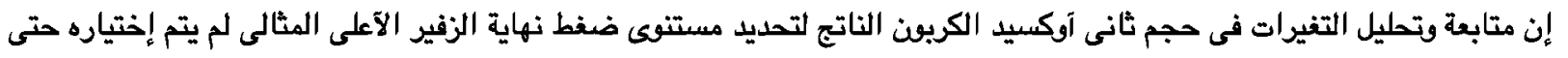

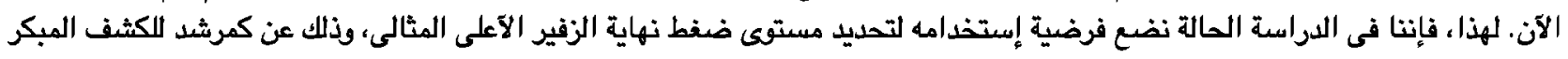

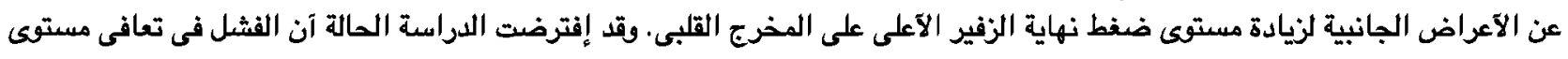

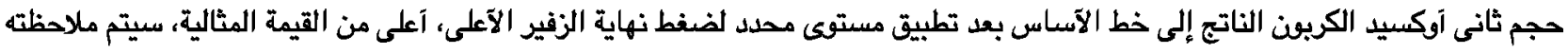
مبكرا قبل إنخفاض المخرج القلى. وقد تم تحديد مستوى ضغط نهاية الزفير الآعلى المثالى بإستخدام المطاوعة الساكنة في مجموعة التحكي. 